\title{
Avaliação do teor de cafeína em folhas e grãos de acessos de café arábica $^{1}$
}

\author{
Evaluation of the caffeine content in leaves and grains of arabica coffee accessions
}

\author{
Alexsandro Lara Teixeira2*, Paulo Eduardo Rodrigues Prado ${ }^{3}$, Kaio Olimpio das Graças Dias ${ }^{3}$, Marcelo Ribeiro \\ Malta $^{4}$ e Flávia Maria Avelar Gonçalves ${ }^{5}$
}

\begin{abstract}
Resumo - O presente trabalho teve como objetivo identificar, dentro do banco de germoplasma do estado de Minas Gerais, acessos de Coffea arabica L. com baixos teores de cafeína e verificar a existência de correlação entre o teor de cafeína dos grãos e de folhas ainda no estádio de mudas, viabilizando a prática da seleção precoce. Foram utilizados 75 acessos de café (cultivares, híbridos e alguns genótipos selvagens) oriundos do banco de germoplasma de café do Estado de Minas Gerais. Para estudo da correlação foram utilizados oito cultivares no delineamento de blocos casualizados com três repetições. Avaliaram-se os teores de cafeína presentes nos grãos e no terceiro e quarto par de folhas verdadeiras. Seis acessos apresentaram teores de cafeína nos grãos menores que $0,88 \%$. Correlações significativas para teor de cafeína foram observadas entre o terceiro $(0,69)$ e quarto par de folhas $(0,92)$ e os grãos. Foram identificados acessos com teores reduzidos de cafeína e boa produtividade de grãos, podendo ser utilizados como genitores em programas de melhoramento. Verificou-se que é possível realizar a seleção precoce para teor de cafeína, em plantas de cafeeiro ainda no estádio de mudas, por meio da avaliação do quarto par de folhas.
\end{abstract}

Palavras-chave - Coffea arabica L. Melhoramento genético. Correlação fenotípica. Seleção precoce.

\begin{abstract}
The aim of this study was to identify, within the germplasm bank of the Minas Gerais state, Coffea arabica L. accessions with low levels of caffeine and check the correlation between grain and leaves in seedling stage, making possible the practice of early selection. Seventy-five coffe accessions (cultivars, hybrids and several wild genotypes) were evaluated from the coffee germplasm bank of the Minas Gerais state. In the correlation study, eight cultivars were used on randomized complete block design with three replications. Were evaluated the caffeine levels in the grains and the third and fourth pair of true leaves. Six accessions had caffeine levels in grains smaller than $0.88 \%$. Was also detected a significant correlation between the caffeine levels in the third (0.69) and fourth (0.92) pair of leaves and grains. Genotypes were identified with low levels of caffeine and great yield may be used as parental in breeding programs. It is possible to perform early selection for caffeine content in coffee plants, still in the seedling stage, by evaluating the fourth pair of leaves.
\end{abstract}

Key words - Coffea arabica L. Genetic breeding. Correlation phenotypic. Early selection.

\footnotetext{
* Autor para correspondência

${ }^{1}$ Recebido para publicação 27/10/2010; aprovado em 07/06/2011

Parte da Tese de Doutorado do primeiro autor

${ }^{2}$ Embrapa Rondônia, BR 364, Km 5,5 - Zona Rural, Caixa Postal 127, Porto Velho-RO, Brasil, 76815-800, alexteixeira@cpafro.embrapa.br

${ }^{3}$ Departamento de Biologia, Universidade Federal de Lavras/UFLA, Pós-Graduação em Genética de Melhoramento de Plantas, Lavras-MG, Brasil,

prado017@yahoo.com.br, kaioolimpio@hotmail.com

${ }^{4}$ Centro Tecnológico do Sul de Minas, EPAMIG, Lavras-MG, Brasil, marcelomalta@epamig.ufla.br

${ }^{5}$ Departamento de Biologia, Universidade Federal de Lavras/UFLA, Lavras-MG, Brasil, avelar@dbi.ufla.br
} 


\section{Introdução}

O consumo de café no mundo está em contínua expansão e cada vez mais o mercado consumidor exige um café com alta qualidade de bebida. Em 2010, o Brasil alcançou 47 milhões de sacas beneficiadas, com um consumo per capita chegando a $4,65 \mathrm{~kg} \mathrm{ano}^{-1}$ de café torrado, o que corresponde a uma média de aproximadamente 78 litros de café para cada brasileiro (ABIC, 2010). Uma pesquisa realizada pela Agência TNS-Interscience (2008) revelou que nove em cada dez brasileiros acima de 15 anos consomem café diariamente, o que torna o café a segunda bebida comercializada com maior aceitação pela população, atrás apenas da água e à frente do refrigerante e do leite. Uma das razões para o elevado consumo de café é devido à presença da cafeína em seus grãos (MAZZAFERA; SILVAROLLA, 2010; RAJU; GOPAL, 1979).

A cafeína age como um estimulante do sistema nervoso central, aumentando a concentração e diminuindo a fadiga. Entretanto, pesquisas revelam que a ingestão de cafeína em excesso pode causar vários distúrbios no organismo como dores de cabeça, irritabilidade, insônia, doenças coronarianas e até evoluir para alguns tipos de câncer (GALLUS et al., 2009; MONTELLA et al., 2009; SIN et al., 2009; TANG et al., 2009). Devido a esses estudos, a procura pelo café descafeinado tem aumentado consideravelmente, sendo até mesmo recomendado por médicos.

Segundo a Associação Brasileira da Indústria do Café - ABIC, o consumo de café industrialmente descafeinado no Brasil é de aproximadamente 1,2\%. Contudo, estima-se que, de todo o café mundialmente comercializado, 10\% destinam-se à descafeinação (ABIC, 2010). Este fato tem especial significado, considerando que o Brasil é o maior produtor mundial de café. Somente nos Estados Unidos, em 1999, a demanda por bebidas sem cafeína, como café e chá verde, chegou a atingir $23 \%$ do setor de bebida desse gênero. (HEILMANN, 2001; SILVAROLLA et al., 2004).

As variações para teor de cafeína encontradas em genótipos de café arábica e robusta estão entre 0,8 a 2,8\% (HEILMANN, 2001). Para ser considerado descafeinado, a legislação brasileira define um teor máximo de $0,1 \%$ de cafeína nos grãos (BRASIL, 1999). Assim, todo o café descafeinado encontrado no mercado é obtido com o uso de solventes químicos, em que a extração da cafeína é realizada nos grãos crus inteiros, antes do processo de torrefação. Esse procedimento deprecia muito a qualidade de bebida do café (ABRAHÃO et al., 2008). Deste modo, a identificação de plantas com boa produção de grãos e baixos teores de cafeína permitiria obter café descafeinado com boa qualidade de bebida.
Já existem alguns trabalhos que almejam a obtenção de cultivares de café com teores reduzidos de cafeína ou descafeinados. Entretanto, até o momento os genótipos desenvolvidos possuem baixa produtividade ou mesmo qualidade de grãos inadequada para um mercado consumidor cada vez mais exigente (NAGAI et al., 2008; PRIOLLI et al., 2008; SILVAROLLA et al., 2004).

Neste contexto, é de suma importância desenvolver cultivares de café com baixos teores de cafeína, com alta produtividade e qualidade de grãos, com o intuito de atender a expansão desse nicho de mercado, oferecendo uma bebida de alta qualidade, sem a adição de reagentes químicos para extração da cafeína.

Diante disso, o presente trabalho teve como objetivos identificar, dentro do banco de germoplasma de café do estado de Minas Gerais, acessos de Coffea arabica L. com baixos teores de cafeína e verificar a existência de correlação entre o teor de cafeína dos grãos e de folhas, ainda no estádio de mudas, viabilizando a prática da seleção precoce.

\section{Material e métodos}

Foram realizados dois experimentos, sendo o primeiro com o objetivo de identificar acessos com baixos teores de cafeína (Experimento A), e o segundo, verificar a correlação entre o teor de cafeína dos grãos e das folhas de mudas de cafeeiro (Experimento B).

O experimento A foi conduzido em Patrocínio, Minas Gerais, situada a $18^{\circ} 56^{\prime} 38^{\prime \prime} \mathrm{S}$ e $46^{\circ} 59^{\prime} 34^{\prime}$ W. O clima da região é classificado como tropical de altitude, Cwa (Köppen), com temperaturas médias anuais de $20,2{ }^{\circ} \mathrm{C}$, precipitação pluvial média de 1.620 $\mathrm{mm}$, com 65 a $70 \%$ desse total concentrados no período de dezembro a março, e altitude média de $972 \mathrm{~m}$. Foram coletados grãos provenientes de 75 acessos de café do banco de germoplasma de café do estado de Minas Gerais, instalado na fazenda experimental da Empresa de Pesquisa Agropecuária de Minas Gerais EPAMIG, em Patrocínio, MG. O delineamento utilizado foi blocos casualizados com duas repetições, espaçamento de 3,5 x 0,8 metros, com dez plantas por parcela. Dentre os acessos avaliados estão 25 cultivares, 36 híbridos e 14 genótipos selvagens introduzidos de outros países. $\mathrm{O}$ período de coleta foi entre os meses de junho a julho de 2009. As adubações foram realizadas de acordo com as recomendações para a cultura do cafeeiro. Foram adotadas as práticas de manejo usualmente empregadas na cultura.

As amostras foram colhidas manualmente (500 gramas por acesso), com frutos no estádio cereja, de no mínimo três plantas diferentes de cada acesso. Em 
seguida, cada amostra foi despolpada e seca em terreiro. Nessa primeira avaliação cada acesso foi representado por uma única amostra sem repetição, portanto, três subamostras foram retiradas dessa amostra única, em forma de replicata, para as análises em laboratório. Uma nova avaliação foi realizada no ano de 2010, apenas com os acessos melhores classificados quanto ao baixo teor de cafeína nos grãos, utilizando o delineamento em blocos casualizados com duas repetições, para a confirmação dos resultados obtidos no ano de 2009. Foram coletados também dados de produção de grãos por parcela $\left(\mathrm{kg} \mathrm{ha}^{-1}\right)$ dos 75 acessos, referente aos anos de 2009 e 2010.

O experimento B foi conduzido em Lavras, Minas Gerais, situada a $21^{\circ} 14$ '43" S e 44'59'59" W. O clima da região é classificado como mesotérmico, Cwa (Köppen), com temperaturas médias anuais de $19,3{ }^{\circ} \mathrm{C}$, precipitação pluvial média de $1.411 \mathrm{~mm}$, com 65 a $70 \%$ desse total concentrados no período de dezembro a março, e altitude média de $919 \mathrm{~m}$. O trabalho foi desenvolvido com amostras extraídas de um experimento já instalado em janeiro de 2004, no Departamento de Agricultura da Universidade Federal de Lavras - DAG/UFLA, em Lavras, MG. O delineamento experimental foi em blocos casualizados, espaçamento de $3,5 \times 0,8$ metros, com três repetições e sete plantas por parcela. Foram utilizadas as seguintes cultivares: Acauã, Catucaí amarelo, Obatã IAC, Oeiras MG, Palma II IBC, Paraíso MG, Robusta e Topázio MG. A coleta dos frutos maduros foi realizada em junho de 2009. As adubações foram realizadas de acordo com as recomendações para a cultura do cafeeiro. Foram adotadas as práticas de manejo usualmente empregadas na cultura.

Cada parcela foi representada por 500 gramas de frutos no estádio cereja. Parte dos frutos foi utilizada para a quantificação da cafeína e o restante para a produção de mudas. Os frutos utilizados na quantificação da cafeína foram secos em estufa de circulação forçada a $65^{\circ} \mathrm{C}$ por 48 horas. Para a formação das mudas, as sementes foram despolpadas e secas à sombra. Em seguida, foram semeadas em sacos plásticos e conduzidas em casa de vegetação. Cada parcela foi representada por dez mudas. A coleta das folhas foi realizada quando as mudas atingiram o quarto par de folhas verdadeiras completamente desenvolvidas. Foram coletados o terceiro e o quarto par de folhas verdadeiras para análise. A escolha dos pares de folhas foi baseada na hipótese de que as maiores concentrações de cafeína estão presentes nos últimos pares de folhas emitidos (RAJU; GOPAL, 1979) e que extração de folhas muito cedo (primeiro e segundo par) poderia prejudicar o desenvolvimento das mudas.

As análises de quantificação do teor de cafeína nos grãos e nas folhas, de ambos os experimentos, foram realizadas no laboratório de qualidade do café da EPAMIG, em Lavras, MG. Todos os grãos foram secos até umidade próxima a $12 \%$. As amostras em grãos foram inicialmente homogeneizadas em moinho de facas até a obtenção de partículas de tamanho reduzido e passaram por peneira de $0,84 \mathrm{~mm}$ de tamanho de abertura de poro. As amostras de folhas foram secas em estufa de circulação forçada a $65^{\circ} \mathrm{C}$ por 48 horas, e posteriormente trituradas em cadinho.

A determinação da cafeína foi realizada utilizando espectrofotometria com comprimento de onda a 273 $\mathrm{nm}$, conforme metodologia descrita por Li et al. (1990). O procedimento constou do seguinte: a) preparo da solução padrão de cafeína em $\mathrm{H}_{2} \mathrm{O}$ a $0 ; 10 ; 25 ; 50 ; 100$ e $150 \mathrm{mg} \mathrm{L}^{-1}$; b) transferência de $200 \mathrm{mg}$ de amostra de tecido vegetal para frasco de vidro de $50 \mathrm{~mL}$; c) adição de $20 \mathrm{~mL}$ de $\mathrm{H}_{2} \mathrm{O}$ e $500 \mathrm{mg}$ de $\mathrm{MgO}$; d) aquecimento por 30 minutos, em banho-maria, a $95{ }^{\circ} \mathrm{C}$, deixou-se resfriar em temperatura ambiente e posteriormente completou-se com água o volume evaporado; e) após decantação do tecido vegetal, transferiu-se $2 \mathrm{~mL}$ de alíquota e/ou de solução padrão de cafeína para tubo de vidro, de $25 \mathrm{~mL}$ com tampa; f) adicionou-se $4 \mathrm{~mL}$ de $\mathrm{CHCl}_{3}$, agitando por 10 minutos e centrifugando; g) transferiu-se $2 \mathrm{~mL}$ da fase orgânica para tubo de vidro; h) evaporou-se o $\mathrm{CHCl}_{3}$ em estufa a $65^{\circ} \mathrm{C}$; i) adicionou-se $10 \mathrm{~mL}$ de $\mathrm{H}_{2} \mathrm{O}$ destilada e fez-se a leitura em espectrofotômetro a $273 \mathrm{~nm}$ e; j) estimou-se a concentração da cafeína através da curva analítica.

Os dados dos teores de cafeína em grãos e folhas (\%) e da produtividade de grãos $\left(\mathrm{kg} \mathrm{ha}^{-1}\right)$ foram submetidos à análise de variância com a significância dos efeitos verificada pelo teste $\mathrm{F}$ a $5 \%$ de probabilidade. Para a produção de grãos realizou-se também a análise conjunta dos anos de 2009 e 2010. A acurácia seletiva $\left(\hat{\mathrm{r}}_{\hat{\mathrm{gg}}}\right)$, determinada por meio da expressão: $\hat{\mathrm{r}}_{\hat{\mathrm{gg}}}=(1-1 / \mathrm{F})^{1 / 2}$, em que F é o valor do teste $\mathrm{F}$ de Snedecor para o efeito de genótipo (RESENDE; DUARTE, 2007), foi estimada para aferir a precisão experimental. As médias dos genótipos foram agrupadas pelo teste de Scott e Knott (1974) a 5\% de significância.

A associação entre os caracteres teor de cafeína no grão e teor de cafeína na folha foi medida pelo coeficiente de correlação linear de Pearson e sua significância foi verificada pela estatística t-student a 5\%. Realizou-se o diagnóstico de multicolinearidade, por meio da matriz de correlação, em que verificou-se uma multicolinearidade fraca $(\mathrm{NC}=53,14)$, o que não denota problemas nas análises. As análises estatísticas foram realizadas no pacote estatístico SAS (Statistical Analysis System) (SAS, 2008).

\section{Resultados e discussão}

No experimento A foi possível observar diferença significativa $(\mathrm{P} \leq 0,01)$ quanto ao teor de cafeína nos 
grãos entre os 75 acessos de café avaliados no ano de 2009 (TAB. 1). A acurácia $\left(\hat{\mathrm{r}}_{\mathrm{gg}}\right)$ e repetibilidade $(\hat{\rho})$ foram de elevada magnitude, mostrando que a precisão experimental foi adequada. O uso da acurácia, como medida de precisão experimental, sugerido por Resende e Duarte (2007), tem a vantagem de não depender da magnitude da média, proporcionando maior segurança na utilização da expressão fenotípica como indicador da variação genotípica.

Quanto à produção de grãos, foi observada diferença significativa entre acessos $(\mathrm{P} \leq 0,05)$. Houve também diferença entre anos, além de uma interação acessos $\mathrm{x}$ anos significativa, indicando que o comportamento dos acessos foi não consistente nos dois anos de avaliação (TAB. 2). A média geral e a herdabilidade $\left(\mathrm{h}^{2}\right)$ foram de $985,17 \mathrm{~kg} \mathrm{ha}^{-1} \mathrm{e}$ $89,57 \%$, respectivamente. A acurácia também mostrou-se elevada $\left(\hat{\mathrm{r}}_{\hat{\mathrm{g} g}}=80 \%\right)$, indicando boa precisão experimental na avaliaçã̃o da produção.
Oito por cento dos acessos avaliados apresentaram valores reduzidos para porcentagem de cafeína nos grãos (<0,88\%), os quais são MG 1019; MG 0228; MG 0890; MG 0453; MG 0139 e MG 0733 (TAB. 3). Dentre estes, encontra-se a cultivar Laurina (MG 0228) que é considerada dentro da espécie Coffea arabica L., a cultivar que apresenta menores teores de cafeína $(0,62 \%)$ (CARVALHO et al., 1988). Heilmann (2001) ressalta que as variações para teor de cafeína em genótipos de café arábica e robusta estão entre 0,8 e $2,8 \%$. Com exceção dos acessos identificados como cultivar (MG 0139 e MG 0228), todos os outros quatro acessos são plantas $F_{1}$ 's oriundas de hibridações, identificadas apenas pelo seu referido código (TAB. 3). A média geral para teor de cafeína nos grãos foi de $1,12 \%$.

Dentre os acessos avaliados, alguns são identificados como cultivares amplamente utilizadas pelos agricultores pelo seu alto potencial produtivo e/ou

Tabela 1 - Resumo da análise de variância quanto ao teor de cafeína nos grãos (\%), em acessos de café arábica, Patrocínio, Minas Gerais, 2009-2010

\begin{tabular}{|c|c|c|c|c|}
\hline \multirow{2}{*}{ FV } & \multicolumn{2}{|c|}{------------Cafeína ${ }^{1}$ (\%) - 2009-------- } & \multicolumn{2}{|c|}{-----------Cafeína² $(\%)$ - 2010----------- } \\
\hline & GL & Quadrado médio & GL & Quadrado médio \\
\hline Blocos & - & - & 1 & 0,0009 \\
\hline Acessos & 74 & $0,0611 * *$ & 8 & $0,0059^{\mathrm{NS}}$ \\
\hline Resíduo & 150 & 0,0031 & 8 & 0,0012 \\
\hline Média & & 1,12 & & 0,89 \\
\hline$\hat{\mathrm{r}}_{\hat{\mathrm{gg}}}(\%)$ & & 97,35 & & 89,19 \\
\hline$\hat{\rho}(\%)$ & & $94,78(92,36 ; 96,54)^{\#}$ & & - \\
\hline $\mathrm{h}^{2}(\%)$ & & - & & $79,55(09,35 ; 95,39)^{\#}$ \\
\hline
\end{tabular}

${ }^{1}$ Referente aos 75 acessos avaliados no ano de 2009. ${ }^{*}$ Intervalo de confiança a $95 \%$ de probabilidade; ${ }^{2}$ Referente aos 9 acessos melhores classificados, reavaliados no ano de 2010; ** Significativo a $1 \%$ pelo teste $\mathrm{F}$. ${ }^{\mathrm{NS}}$ Não significativo pelo teste $\mathrm{F}(\mathrm{P} \leq 0,05)$

Tabela 2 - Resumo da análise de variância conjunta quanto à produção de grãos ( $\left.\mathrm{kg} \mathrm{ha}^{-1}\right)$, dos 75 acessos de café arábica avaliados nos anos de 2009 e 2010, Patrocínio, Minas Gerais, 2010

\begin{tabular}{ccc}
\hline FV & \multicolumn{2}{c}{ Produção $\left(\mathrm{kg} \mathrm{ha}^{-1}\right)$} \\
\cline { 2 - 4 } & GL & Quadrado médio \\
\hline Acessos & 74 & $1537221,53^{* *}$ \\
Anos & 1 & $634822,08^{*}$ \\
Acessos x Anos & 74 & $553369,36^{* *}$ \\
Resíduo & 148 & 160237,79 \\
Média & & 985,17 \\
$\mathrm{r}_{\hat{\mathrm{gg}}}(\%)$ & & 80,00 \\
$\mathrm{~h}^{2}(\%)$ & & $89,57(84,29 ; 92,90)^{\#}$ \\
\hline
\end{tabular}

** e * Significativo a 1\% e 5\%, respectivamente, pelo teste $\mathrm{F}$; ${ }^{*}$ Intervalo de confiança a $95 \%$ de probabilidade 
Tabela 3 - Relação dos 75 acessos de café arábica, em ordem crescente quanto ao teor de cafeína nos grãos ${ }^{(1)}$ (2009) e produção de café beneficiado ${ }^{(1)}\left(\mathrm{kg} \mathrm{ha}^{-1}\right)$ (2009 e 2010), oriundos do Banco de Germoplasma de Café do estado de Minas Gerais, Patrocínio, Minas Gerais, 2009-2010

\begin{tabular}{|c|c|c|c|c|c|}
\hline Acesso & Cafeína (\%) & Produção $\left(\mathrm{kg} \mathrm{ha}^{-1}\right)$ & Acesso & Cafeína (\%) & Produção $\left(\mathrm{kg} \mathrm{ha}^{-1}\right)$ \\
\hline MG 1019 & $0,8242 \mathrm{a}$ & $320,87 \mathrm{~d}$ & MG 0417 & $1,1314 \mathrm{~d}$ & $1049,11 \mathrm{c}$ \\
\hline MG 0228 & $0,8381 \mathrm{a}$ & $959,82 \mathrm{~d}$ & MG 0783 & $1,1383 \mathrm{~d}$ & $376,67 \mathrm{~d}$ \\
\hline MG 0890 & $0,8409 \mathrm{a}$ & $118,58 \mathrm{~d}$ & MG 0720 & $1,1446 \mathrm{~d}$ & $1032,37 \mathrm{c}$ \\
\hline MG 0453 & $0,8610 \mathrm{a}$ & $904,02 \mathrm{~d}$ & MG 0512 & $1,1550 \mathrm{~d}$ & $1074,22 \mathrm{c}$ \\
\hline MG 0139 & $0,8680 \mathrm{a}$ & $3828,13 \mathrm{a}$ & MG 0557 & $1,1598 \mathrm{~d}$ & $1060,27 \mathrm{c}$ \\
\hline MG 0733 & $0,8735 \mathrm{a}$ & $1130,03 \mathrm{c}$ & MG 0181 & $1,1661 \mathrm{~d}$ & $881,70 \mathrm{~d}$ \\
\hline MG 1063 & $0,8986 \mathrm{~b}$ & $153,46 \mathrm{~d}$ & MG 1156 & $1,1710 \mathrm{~d}$ & $864,96 \mathrm{~d}$ \\
\hline MG 0149 & $0,9145 \mathrm{~b}$ & $1741,07 \mathrm{~b}$ & MG 0206 & $1,1800 \mathrm{~d}$ & $535,71 \mathrm{~d}$ \\
\hline MG 0245 & $0,9333 \mathrm{~b}$ & $1573,66 \mathrm{~b}$ & MG 0145 & $1,1814 \mathrm{~d}$ & $691,97 \mathrm{~d}$ \\
\hline MG 0811 & $0,9361 \mathrm{~b}$ & $418,53 \mathrm{~d}$ & MG 0187 & $1,1960 \mathrm{~d}$ & $1026,79 \mathrm{c}$ \\
\hline MG 0240 & $0,9389 \mathrm{~b}$ & $156,25 \mathrm{~d}$ & MG 0110 & $1,1995 \mathrm{~d}$ & $2008,93 \mathrm{~b}$ \\
\hline MG 0265 & $0,9472 \mathrm{~b}$ & $78,12 \mathrm{~d}$ & MG 0570 & $1,2064 \mathrm{~d}$ & $669,64 \mathrm{~d}$ \\
\hline MG 0533 & $0,9590 \mathrm{~b}$ & $474,33 \mathrm{~d}$ & MG 0231 & $1,2085 \mathrm{~d}$ & $636,16 \mathrm{~d}$ \\
\hline MG 0002 & $0,9674 \mathrm{c}$ & $1116,07 \mathrm{c}$ & MG 0215 & $1,2092 \mathrm{~d}$ & $446,43 \mathrm{~d}$ \\
\hline MG 0765 & $0,9715 \mathrm{c}$ & $753,35 \mathrm{~d}$ & MG 0248 & $1,2189 \mathrm{e}$ & $1473,22 \mathrm{c}$ \\
\hline MG 0236 & $1,0007 \mathrm{c}$ & $970,99 \mathrm{~d}$ & MG 1171 & $1,2203 \mathrm{e}$ & $558,04 \mathrm{~d}$ \\
\hline MG 1170 & $1,0042 \mathrm{c}$ & $739,40 \mathrm{~d}$ & MG 0100 & $1,2300 \mathrm{e}$ & $1372,77 \mathrm{c}$ \\
\hline MG 0118 & $1,0104 \mathrm{c}$ & $1551,34 \mathrm{~b}$ & MG 0129 & $1,2300 \mathrm{e}$ & $1160,72 \mathrm{c}$ \\
\hline MG 0188 & $1,0118 \mathrm{c}$ & $1194,20 \mathrm{c}$ & MG 0131 & $1,2356 \mathrm{e}$ & $1316,96 \mathrm{c}$ \\
\hline MG 1059 & $1,0153 \mathrm{c}$ & $390,63 \mathrm{~d}$ & MG 0162 & $1,2439 \mathrm{e}$ & $1674,11 \mathrm{~b}$ \\
\hline MG 0421 & $1,0278 \mathrm{c}$ & $1183,04 \mathrm{c}$ & MG 0264 & $1,2439 \mathrm{e}$ & $1082,59 \mathrm{c}$ \\
\hline MG 0971 & $1,0341 \mathrm{c}$ & $432,48 \mathrm{~d}$ & MG 0602 & $1,2467 \mathrm{e}$ & $1367,19 \mathrm{c}$ \\
\hline MG 0230 & $1,0362 \mathrm{c}$ & $1763,39 \mathrm{~b}$ & MG 0175 & $1,2481 \mathrm{e}$ & $1294,64 \mathrm{c}$ \\
\hline MG 1049 & $1,0417 \mathrm{c}$ & $251,12 \mathrm{~d}$ & MG 0158 & $1,2488 \mathrm{e}$ & $1316,97 \mathrm{c}$ \\
\hline MG 1065 & $1,0466 \mathrm{c}$ & $265,07 \mathrm{~d}$ & MG 0577 & $1,2502 \mathrm{e}$ & $781,25 \mathrm{~d}$ \\
\hline MG 1166 & $1,0487 \mathrm{c}$ & $265,07 \mathrm{~d}$ & MG 0015 & $1,2592 \mathrm{e}$ & $1841,52 \mathrm{~b}$ \\
\hline MG 0170 & $1,0639 \mathrm{c}$ & $658,48 \mathrm{~d}$ & MG 0833 & $1,2627 \mathrm{e}$ & $585,94 \mathrm{~d}$ \\
\hline MG 0803 & $1,0674 \mathrm{c}$ & $516,18 \mathrm{~d}$ & MG 1084 & $1,2627 \mathrm{e}$ & $237,17 \mathrm{~d}$ \\
\hline MG 1005 & $1,0674 \mathrm{c}$ & $669,64 \mathrm{~d}$ & MG 0204 & $1,2696 \mathrm{e}$ & $357,14 \mathrm{~d}$ \\
\hline MG 0251 & $1,0883 \mathrm{c}$ & $1104,91 \mathrm{c}$ & MG 0176 & $1,2724 \mathrm{e}$ & $1417,41 \mathrm{c}$ \\
\hline MG 1167 & $1,0931 \mathrm{c}$ & $460,38 \mathrm{~d}$ & MG 0544 & $1,2759 \mathrm{e}$ & $1492,75 \mathrm{c}$ \\
\hline MG 0617 & $1,1077 \mathrm{~d}$ & $1199,78 \mathrm{c}$ & MG 0863 & $1,3239 \mathrm{f}$ & $669,64 \mathrm{~d}$ \\
\hline MG 0119 & $1,1098 \mathrm{~d}$ & $1863,84 \mathrm{~b}$ & MG 0309 & $1,3259 \mathrm{f}$ & $1127,23 \mathrm{c}$ \\
\hline MG 0017 & $1,1112 \mathrm{~d}$ & $1796,88 \mathrm{~b}$ & MG 0117 & $1,3489 \mathrm{f}$ & $1908,48 \mathrm{~b}$ \\
\hline MG 0526 & $1,1133 \mathrm{~d}$ & $934,71 \mathrm{~d}$ & MG 0141 & $1,3586 \mathrm{f}$ & $1171,88 \mathrm{c}$ \\
\hline MG 1062 & $1,1161 \mathrm{~d}$ & $209,27 \mathrm{~d}$ & MG 0006 & $1,3746 \mathrm{f}$ & 1908,48 b \\
\hline MG 0241 & $1,1195 \mathrm{~d}$ & $736,61 \mathrm{~d}$ & MG 0153 & $1,3906 \mathrm{f}$ & $1986,61 \mathrm{~b}$ \\
\hline MG 0237 & $1,1272 \mathrm{~d}$ & $546,88 \mathrm{~d}$ & & & \\
\hline
\end{tabular}

(1) Médias seguidas de letras iguais, na vertical, pertencem ao mesmo agrupamento pelo teste de Scott e Knott, a 5\% de significância 
pela boa qualidade de bebida (Bourbon, Catuaí Vermelho, Catucaí Amarelo, Caturra Vermelho, Obatã Amarelo). A média de produção para as referidas cultivares foi de $1.209,08 \mathrm{~kg} \mathrm{ha}^{-1}$. No entanto, os acessos apresentaram teores de cafeína acima de 1,00\%. Esses teores elevados de cafeína afetam sobremaneira o mercado consumidor de cafés descafeinados, já que há necessidade de se extrair a cafeína presente nos grãos para abastecer o mercado, a um custo médio de U\$0,50/kg (HEIN; GATZWEILER, 2006). Segundo Abrahão et al. (2008) a descafeinação, com o uso de solventes químicos, altera a concentração dos compostos bioativos presentes na bebida do café, afetando a qualidade sensorial e tornando esta uma bebida descaracterizada e de qualidade inferior.

Como já comentado, a legislação brasileira exige um teor máximo de $0,1 \%$ de cafeína nos grãos para que o café seja considerado descafeinado (BRASIL, 1999). Portanto, até o momento, não existem cultivares registradas de café com teores $\leq 0,1 \%$. Silvarolla et al. (2004), avaliando 3.000 acessos de Coffea arabica oriundos da Etiópia, identificaram três plantas mutantes completamente livres de cafeína. Todavia, esses genótipos não apresentaram desempenho satisfatório nas nossas condições, mostrando que é necessário investir no melhoramento genético ou mesmo utilizá-los como genitores em programas de melhoramento com o intuito de obter cultivares livres de cafeína.

Os nove acessos com melhor classificação quanto ao baixo teor de cafeína nos grãos, reanalisados no ano de 2010, apresentaram valores semelhantes aos observados no ano anterior, com média de $0,89 \%$ (TAB. 4). Não foi detectada diferença significativa entre os mesmos (TAB. 1). Com relação à produção, a média observada desses acessos foi de $1.192,18 \mathrm{~kg} \mathrm{ha}^{-1}$, produtividade esta semelhante às daqueles acessos representados por cultivares. Destaque para o acesso MG 0139 com produtividade de $3.828,13 \mathrm{~kg} \mathrm{ha}{ }^{-1}$. Os acessos MG 0149 e MG 0245 também apresentaram produção satisfatória (TAB. 3). Já os outros acessos apresentaram produtividades abaixo da média, o que poderia causar demora no processo de melhoramento. Produções baixas também foram comentadas por Carvalho et al. (1988) para o acesso MG 0228 (cv. Laurina), que ressaltaram ainda a má qualidade dos grãos para essa cultivar. Diante do exposto, os acessos MG 0139; MG 0149 e MG 0245, apesar de não apresentarem teores de cafeína dentro do exigido para o mercado descafeinado, poderiam ser utilizados como genitores na obtenção de uma população de melhoramento com teores reduzidos de cafeína nos grãos.

No experimento B, em que se procurou detectar associações significativas entre os teores de cafeína presentes nos grãos e no terceiro e quarto par de folhas, foi possível observar estimativas de correlações altas e positivas entre os teores de cafeína presente nos grãos e no terceiro $(\mathrm{r}=0,69)$ e quarto $(\mathrm{r}=0,92)$ par de folhas (TAB. 5). Na Figura 1 é possível visualizar as concentrações de cafeína nos grãos, no terceiro e no quarto par de folhas.

Tabela 4 - Nove acessos de café arábica com melhor classificação quanto ao baixo teor de cafeína nos grãos ${ }^{(1)}$ (\%) no ano de 2009, reavaliados em 2010, Patrocínio, Minas Gerais, 2009-2010

\begin{tabular}{cccc}
\hline \multirow{2}{*}{ Rank } & \multirow{2}{*}{ Acesso } & \multicolumn{2}{c}{ Cafeína (\%) } \\
\cline { 3 - 4 } & & 2009 & 2010 \\
\hline 1 & MG 1019 & $0,8242 \mathrm{a}$ & $0,8717 \mathrm{a}$ \\
2 & MG 0228 & $0,8381 \mathrm{a}$ & $0,8444 \mathrm{a}$ \\
3 & MG 0890 & $0,8409 \mathrm{a}$ & $0,9288 \mathrm{a}$ \\
4 & MG 0453 & $0,8610 \mathrm{a}$ & $0,8014 \mathrm{a}$ \\
5 & MG 0139 & $0,8680 \mathrm{a}$ & $0,8874 \mathrm{a}$ \\
6 & MG 0733 & $0,8735 \mathrm{a}$ & $0,8655 \mathrm{a}$ \\
7 & MG 1063 & $0,8986 \mathrm{~b}$ & $0,9796 \mathrm{a}$ \\
8 & MG 0149 & $0,9145 \mathrm{~b}$ & $0,9695 \mathrm{a}$ \\
9 & MG 0245 & $0,9333 \mathrm{~b}$ & $0,8256 \mathrm{a}$ \\
\hline Média & & 0,87 & 0,89 \\
\hline
\end{tabular}

(1) Médias seguidas de letras iguais, na vertical, pertencem ao mesmo agrupamento pelo teste de Scott e Knott, a 5\% de significância

Tabela 5 - Estimativas das correlações fenotípicas de Pearson entre os teores de cafeína nos grãos e no terceiro par de folhas e quarto par de folhas de mudas, Lavras, Minas Gerais, 2009

\begin{tabular}{cccc}
\hline & Grãos & $\begin{array}{c}\text { Terceiro par } \\
\text { de folhas }\end{array}$ & $\begin{array}{c}\text { Quarto par } \\
\text { de folhas }\end{array}$ \\
\hline $\begin{array}{c}\text { Grãos } \\
\text { Terceiro par } \\
\text { de folhas }\end{array}$ & 1,00 & $0,69 *$ & $0,92^{* *}$ \\
$\begin{array}{c}\text { Quarto par } \\
\text { de folhas }\end{array}$ & 1,00 & $0,83^{* *}$ \\
\hline
\end{tabular}

** e * Significativo a $1 \%$ e $5 \%$, respectivamente, pelo teste $\mathrm{t}$

A estimativa do coeficiente de determinação $\left(\mathrm{R}^{2}\right)$ encontrado entre o teor de cafeína dos grãos e do terceiro par de folhas não foi expressivo $\left(\mathrm{R}^{2}=0,47\right)$. Pela Figura $2 \mathrm{~A}$ observa-se que os dados não se ajustaram bem à equação da reta. Já para o teor de cafeína dos grãos e do quarto par de folhas, a estimativa do coeficiente de determinação foi de elevada magnitude $\left(\mathrm{R}^{2}=0,85\right)$. Verifica-se que a 
concentração de cafeína presente nos grãos aumentou linearmente com o aumento dos teores de cafeína no quarto par de folhas (FIG. 2B). Esses resultados se aproximam, em parte, dos trabalhos descritos por Chaves et al. (2004), em que os autores avaliaram o teor de cafeína no primeiro e terceiro par de folhas e nos grãos, e também detectaram correlação significativa entre essas variáveis. No entanto, houve um melhor ajuste dos dados entre os teores de cafeína do terceiro par de folhas e dos grãos $\left(\mathrm{R}^{2}=0,95\right)$. Isso reforça a hipótese de que existe uma maior concentração de cafeína nas folhas mais jovens, ou seja, no último par de folhas emitido.
$\mathrm{Na}$ presença de correlação, a seleção indireta para teor de cafeína torna-se praticável, viabilizando a prática da seleção precoce. O emprego dessa técnica é muito importante, visto que, em espécies perenes o número de anos para se completar um ciclo seletivo é o principal entrave dos programas de melhoramento. Outros trabalhos têm sido realizados com este mesmo objetivo, estudando a estimativa da eficiência da seleção na idade juvenil e correspondência na idade adulta (FARIAS NETO et al., 2003; MACHADO et al., 2008).
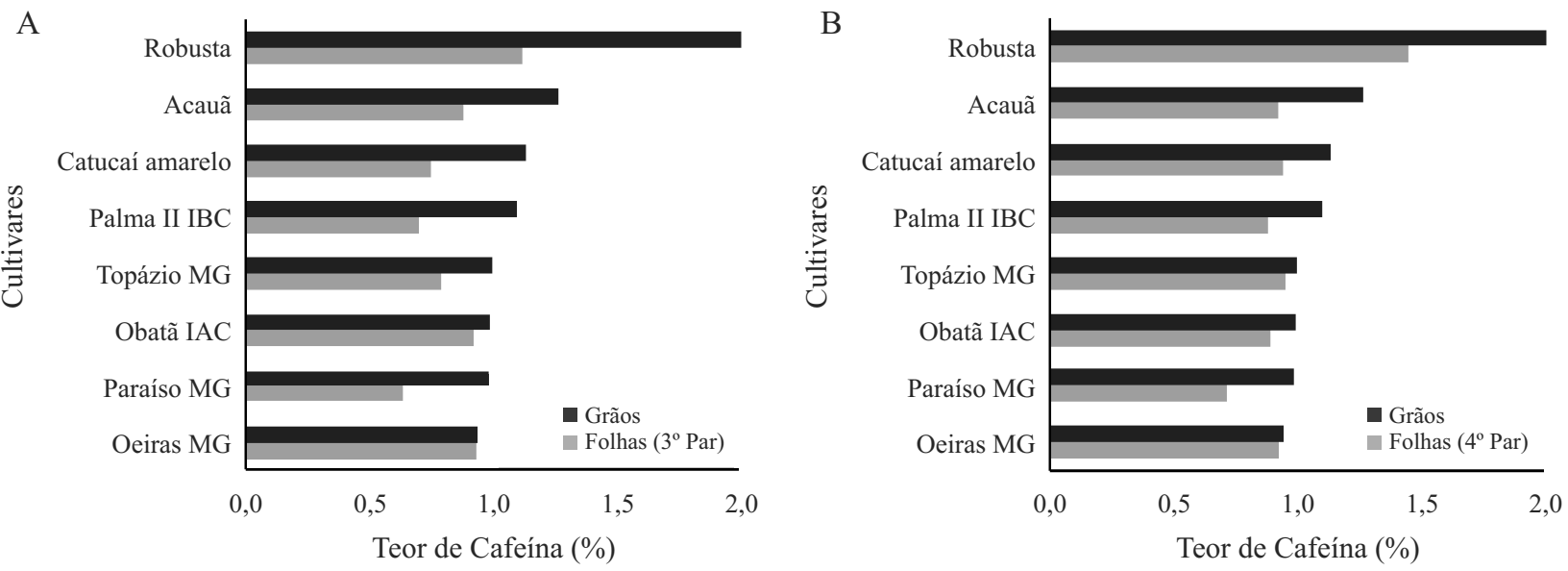

Figura 1 - Comparativo entre os teores de cafeína (\%) presente nos grãos com o terceiro par de folhas (A) e quarto par de folhas (B) de mudas, das oito cultivares avaliadas, Lavras, Minas Gerais, 2009

A

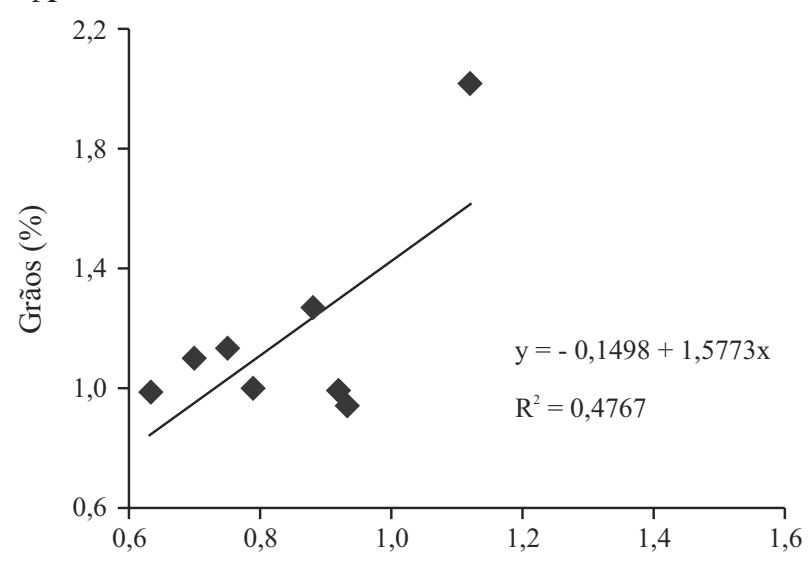

Folhas-terceiro par (\%)

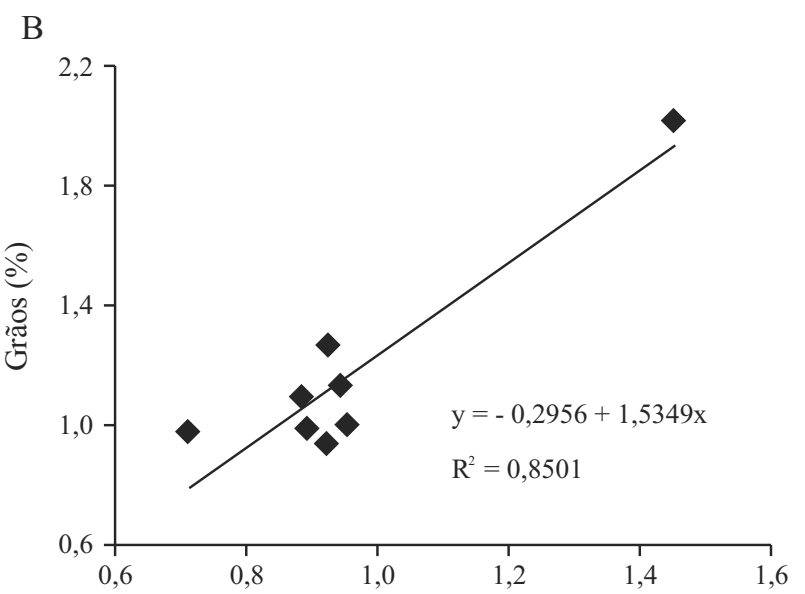

Folhas-quarto par (\%)

Figura 2 - Regressão linear entre os teores de cafeína (\%) do terceiro par de folhas (A) e quarto par de folhas (B) de mudas com os grãos, Lavras, Minas Gerais, 2009 
Constatou-se que a concentração de cafeína presente no quarto par de folhas (último par de folhas avaliado) é maior que a concentração do terceiro par de folhas. Raju e Gopal (1979) encontraram a mesma tendência e observaram maiores níveis de cafeína em folhas jovens em relação às folhas velhas. Já Chaves et al. (2004) observaram resultados diferentes, o que mostra que as folhas do primeiro par são mais ricas em cafeína do que as folhas do terceiro par.

A partir dos resultados, pode-se inferir que é possível realizar a seleção precoce para teor de cafeína, em plantas de cafeeiro, a partir da avaliação do $4^{\circ}$ par de folhas de mudas. Isso torna o processo de seleção mais dinâmico, ou seja, pode-se realizar um descarte dos genótipos indesejáveis, reduzindo custos, tempo e mão de obra nos programas de melhoramento genético.

Por meio do intercruzamento entre os acessos identificados com baixos teores de cafeína, é possível conduzir uma população visando à seleção de genótipos com teores cada vez mais reduzidos, ou mesmo livres de cafeína. No entanto, Nagai et al. (2008) sugerem que além da cafeína, a seleção para produtividade e qualidade de bebida devem ser realizadas simultaneamente, a fim de atender as exigências do mercado consumidor. A seleção baseada no teor de cafeína presente nas folhas, ainda no estágio de mudas, poderia auxiliar o melhorista nas tomadas de decisão, reduzindo os custos na condução das populações segregantes.

O desenvolvimento de uma cultivar livre de cafeína exerceria um forte impacto no mercado mundial de café, já que segundo a ABIC (2010) 10\% do total comercializado destinam-se a descafeinação. Isso proporcionaria aos consumidores um café descafeinado, com menor custo, além de excelente qualidade de bebida.

\section{Conclusões}

1. Foram identificados acessos com teores reduzidos de cafeína e boa produtividade de grãos;

2. Foi detectada correlação alta e positiva entre o teor de cafeína dos grãos e do $4^{\circ}$ par de folhas de mudas, o que evidencia a possibilidade de realizar a seleção precoce para teor de cafeína, em plantas de cafeeiro, ainda no estádio de mudas.

\section{Agradecimentos}

Os autores agradecem a EPAMIG e à UFLA pela disponibilização da infraestrutura e equipamentos, e às agências de fomento CAPES, CNPq e FAPEMIG pelo auxílio financeiro.

\section{Referências}

ASSOCIAÇÃO BRASILEIRA DA INDÚSTRIA DO CAFÉ (ABIC). Estatísticas - Produção Agrícola. 2010. Disponível em: $<$ http://www.abic.com.br/estatisticas.html $>$. Acesso em: 10 dez. 2010.

ABRAHÃO, S. A. et al. Compostos Bioativos em café integral e descafeinado e qualidade sensorial da bebida. Pesquisa Agropecuaria Brasileira, v. 43, n. 12, p. 17991804, 2008.

BRASIL. Portaria $n^{\circ}$ 377, de 26 de abril de 1999. Regulamento técnico para fixação de identificação e qualidade de café torrado em grão e café torrado e moído. Diário Oficial da União, Brasília, n. 80, p. 22, 29 abr. 1999. Seção 1.

CARVAlHO, A.; FAZUOLI, L. C.; MAZZAFERA, P. Produtividade de progênies derivadas de hibridação dos cultivares Laurina e Mundo Novo. Bragantia, v. 47, n. 02, p. 213-222, 1988.

CHAVES, J. C. D. et al. Estimativa do teor de cafeína nas sementes de café baseada na sua concentração nas folhas de mudas e de plantas adultas. Acta Scientiarum. Agronomy, v. 26, n. 03, p. 287-292, 2004.

FARIAS NETO, J. T.; CASTRO, A. W. V.; BIANCHETTI, A. Aplicação da seleção precoce em famílias de meios irmãos de taxi-branco. Acta Amazonica, v. 33, n. 01, p. 8591, 2003.

GALLUS, S. et al. Coffee, black tea and risk of gastric cancer. Cancer Causes and Control, v. 20, n. 08, p. 1-6, 2009.

HEILMANN, W. Tecnology II: decaffeination of coffee. In: CLARK, R. J.; VITZTUM, O. G. (Ed.). Coffee: Recent development. Oxford: Blackwell Science, 2001. p. 108-124.

HEIN, L.; GATZWEILER, F. The economic value of coffee (Coffea arabica) genetic resources. Ecological Economics, v. 60, n. 01, p. 176-185, 2006.

LI, S.; BERGER, J.; HARTLAND, S. UV spectrophotometric determination of theobromine and caffeine in cocoa beans. Analytica Chimica Acta, v. 232, n. 01, p. 409-412, 1990.

MACHADO, C. D. F. et al. Identificação de genótipos de feijão-caupi quanto à precocidade, arquitetura da planta e produtividade de grãos. Revista Ciência Agronômica, v. 39, n. 01, p. 114-123, 2008.

MAZZAFERA, P.; SILVAROLLA, M. B. Caffeine content variation in single green Arabica coffee seeds. Seed Science Research, v. 20, n. 03, p. 163-167, 2010.

MONTELLA, M. et al. Coffee, decaffeinated coffee, tea intake, and risk of renal cell cancer. Nutrition and Cancer, v. 61, n. 01, p. 76-80, 2009. 
NAGAI, C. et al. Production of a new low-caffeine hybrid coffee and the biochemical mechanism of low caffeine accumulation. Euphytica, v. 164, n. 01, p. 133-142, 2008.

PRIOLLI, R. H. G. et al. Caffeine inheritance in interspecific hybrids of Coffea arabica x Coffea canephora (Gentianales, Rubiaceae). Genetics and Molecular Biology, v. 31, n. 02, p. 498-504, 2008.

RAJU, K. I.; GOPAL, N. H. Distribution of caffeine in arabica and robusta coffee plants. Journal of Coffee Research, v. 09, n. 04, p. 83-90, 1979.

RESENDE, M. D. V.; DUARTE, J. B. Precisão e controle de qualidade em experimentos de avaliação de cultivares. Pesquisa Agropecuária Tropical, v. 37, n. 03, p. 182-194, 2007.

SAS. SAS/STAT ${ }^{\circledR}$ 9.2 User's Guide. Version 9.2, Cary, NC: SAS Institute Inc., 2008. 584p.
SCOTT, A. J.; KNOTT, M. A. Cluster analyses method for grouping means in the analyses of variance. Biometrics, v. 30, n. 03, p. 507-512, 1974.

SILVAROLLA, M. B.; MAZZAFERA, P.; FAZUOLI, L. C. A naturally decaffeinated arabica coffee. Nature, v. 429, n. 6994 , p. 826, 2004.

SIN, C. W. M.; HO, J. S. C.; CHUNG, J. W. Y. Systematic review on the effectiveness of caffeine abstinence on the quality of sleep. Journal of Clinical Nursing, v. 18, n. 01, p. 13-21, 2009.

TANG, N. et al. Coffee consumption and risk of lung cancer: A meta-analysis. Lung Cancer, v. 67, n. 01, p. 17-22, 2009.

TNS-INTERSCIENCE. Tendências do Consumo de Café no Brasil., 2008. Disponível em: <http://www.abic.com.br/estat_ pesquisas.html>. Acesso em: 23 jun. 2010. 